\title{
Nursing Care Management Strategies in Isolation Wards during the COVID-19 Outbreak
}

\author{
Zhenghua Zhao*, Xing Lan*, Qinghong Chen*, Chengying Li, Tingting Wang, Xiangdong Chen\#, \\ Shanglong Yao"
}

Department of Anesthesiology, Union Hospital, Tongji Medical College, Huazhong University of Science and Technology, Wuhan, China

Email: "ysltian@qq.com

How to cite this paper: Zhao, Z.H., Lan, X., Chen, Q.H., Li, C.Y., Wang, T.T., Chen, X.D. and Yao, S.L. (2021) Nursing Care Management Strategies in Isolation Wards during the COVID-19 Outbreak. Open Journal of Nursing, 11, 249-257. https://doi.org/10.4236/ojn.2021.114022

Received: March 11, 2021

Accepted: April 22, 2021

Published: April 25, 2021

Copyright $\odot 2021$ by author(s) and Scientific Research Publishing Inc. This work is licensed under the Creative Commons Attribution-NonCommercial International License (CC BY-NC 4.0). http://creativecommons.org/licenses/by-nc/4.0/

\section{Open Access}

\begin{abstract}
Coronavirus disease 2019 (COVID-19) is highly infectious and has spread worldwide. Medical staff may be exposed to the infection under circumstances of medical supply shortages and improper protection. How to better protect medical staff has become the focus of all walks of life. Therefore, during the COVID-19 outbreak, timely adjustments and optimization of nursing management strategies in isolation wards are important for improving care quality and reducing the infection of medical staff. Based on a literature review and clinical nursing management practices, this article summarizes the nursing management strategies in isolation wards during the COVID-19 outbreak, aiming to provide references for clinical nursing managers.
\end{abstract}

\section{Keywords}

Nursing Care Management, Isolation Ward, COVID-19, Patient

Management, Care Quality Management

\section{Introduction}

Coronavirus disease 2019 (COVID-19) can be transmitted through respiratory droplets and close contact and may also be transmitted through aerosols in a relatively closed environment when exposed to high concentrations of aerosols for a long time. The risk of the person-to-person spread of severe acute respiratory syndrome coronavirus 2 (SARS-CoV-2) is high [1]. And the entire population is generally susceptible [2]. The World Health Organization (WHO) has reported that the virus has infected over 18 million people, caused over 709,511 deaths, and affected 216 countries around the world [3]. According to the cur*All authors contributed equally to this paper.

${ }^{*}$ Corresponding authors. 
rent clinical data, the incubation period of SARS-CoV-2 is 1 - 14 days [4]. The main clinical manifestations of infected patients include fever, dry cough, and muscle aches or fatigue. A small number of patients may have abundant expectoration, headache, hemoptysis and diarrhea. Over half of the patients have difficulty breathing at approximately 8 days after disease onset. In severe cases, patients can rapidly progress to acute respiratory distress syndrome (ARDS), septic shock, coagulation dysfunction and multiple organ failure (MOF) [5] [6] [7]. During the COVID-19 outbreak in Wuhan, I directly participated in the care and management of COVID-19 patients as the director of the nursing team working in the isolation ward of a designated hospital in Wuhan, and zero infection among the team members was observed. Based on a literature review and our practical experience, the article summarizes the nursing care management strategies in isolation wards during the COVID-19 pandemic from the following 6 aspects: patient management, staff management, ward environment and contaminant disinfection management, medical protective equipment and waste management, ward layout management and nursing care quality management.

\section{Nursing Care Management Strategies in Isolation Wards}

\subsection{Patient Management}

For patient management, a stratified nursing care strategy should be adopted. The disease conditions of the patients should be comprehensively evaluated according to the available medical resources. Patients should be classified into 4 categories based on disease severity, i.e., mild, common, severe and critical [4].

Patients with mild disease should be given guidance on medication and diet, and instructions on personal protection, such as proper use of masks, proper cough etiquette, and hand hygiene. They should mainly be treated with oral medications. Patients should be guided to exercise properly inside the ward to improve their immunity, such as turning over on the bed, moving around indoors playing Tai Chi, Baduanjin and Wuqinxi which are sets of medical and healing exercises created by ancient people [8]. These exercises can prevent complications, such as deep vein thrombosis caused by long-term bed rest, and are beneficial to the recovery of pulmonary function.

Common patients should stay in bed as much as possible during the onset of the disease, reduce moving, and put them in a comfortable supine or semi-recumbent position [4]. Operations need to be relatively concentrated to avoid patients' fatigue and ensure their adequate sleep. According to the doctor's advice, the patient should be given supportive treatment such as antiviral or traditional Chinese medicine. The patient's vital signs, blood oxygen saturation, especially the changes in body temperature should be closely monitored. The temperature should be measured every $2 \mathrm{~h}$ for patients with a high fever. Patients with temperature higher than $38.5^{\circ} \mathrm{C}$ can be given ice compress, ethanol bath and other physical cooling methods.

Severe patients should receive supportive treatment, including antiviral medi- 
cations, immunoglobins and hormones, in order to maintain the water balance, electrolyte balance and acid-base balance. Additionally, patients with hypoxia or negative nitrogen balance should be given oxygen through nasal catheters or masks, and their vital signs should be closely monitored, including regular routine blood, blood biochemistry, myocardial injury marker, C-reactive protein (CRP) and blood gas analyses, etc. When necessary, they should also undergo imaging examinations.

Patients with critical disease should be treated with noninvasive or invasive ventilators; furthermore, these patients often have respiratory distress and low blood oxygen saturation, which should be closely monitored. Lung protective ventilation therapy was performed to reduce ventilator-associated lung injury, such as low tidal volume ( $6-8 \mathrm{ml} / \mathrm{kg}$ ), low inspiratory pressure (plateau pressure $\leq 30 \mathrm{~cm} \mathrm{H}_{2} \mathrm{O}$ ), appropriate level of positive end-expiratory pressure (PEEP) and oxygen uptake concentration [9]. The oxygen concentration of the ventilator should be adjusted promptly, and the ventilation indexes of the patients should be closely monitored. When the ventilator alarm sounds, the cause of the alarm should be investigated so that each parameter can be coordinated to avoid counteraction between the ventilator and patient. To effectively prevent nosocomial infection, a disposable closed suctioning tube should be used for sputum suction.

SARS-CoV-2 is a novel and highly infectious virus. Patients are prone to panic and anxiety due to insufficient knowledge of the virus. Nursing staff should provide psychological care to help patients maintain an optimistic attitude in defeating the disease. We need to pay attention to our behavior and do not discriminate against patients. Patients' cognition, emotions and behaviors should be regularly evaluated so that nursing staff can provide emotional support to ease patient's uncertainty and anxiety.

\subsection{Staff Management}

There were 41 nurses in the ward, including 2 head nurses, 12 supervisor nurses, 15 nurse practitioners and 12 nurses. The staff was divided into 5 groups according to clinical nursing care tasks, the specific responsibilities are shown in Table 1. A previous study indicated that designating safety supervisors to supervise and guide medical staff regarding wearing and taking off personal protective equipment (PPE) can reduce the infection rate of the medical staff [10]. Due to a nursing staff shortage, the staff of the Infection Management Department of the hospital undertook the work of safety supervisors. 11 safety supervisors should be assigned to supervise and guide the medical staff in regard to wearing and taking off protective equipment.

As a public health emergency, COVID-19 could bring psychological stress to the nursing staff on the front lines fighting against the disease, causing psychological problems, such as anxiety, depression and suspicion [11]. Previous studies have shown that $13.7 \%$ of doctors have symptoms of acute stress disorder (ASD) during wartime and that the risk of post-traumatic stress disorder (PTSD) among medical staff who have not received psychological intervention is 2.7 times 
Table 1. Nursing staff duties.

\begin{tabular}{|c|c|c|}
\hline Group & Staff number & Duties \\
\hline A & 2 & $\begin{array}{l}\text { Responsible for the overall management of the ward, including scheduling } \\
\text { nursing staff, allocating beds in the ward, implementing protective } \\
\text { measures, supervising nursing care quality, managing medical items and } \\
\text { handling emergency situations. }\end{array}$ \\
\hline B & 6 & $\begin{array}{l}\text { Responsible for patient admission, handling medical instructions, checking } \\
\text { treatments, arranging examinations and completing admissions and } \\
\text { discharges. }\end{array}$ \\
\hline C & 3 & $\begin{array}{l}\text { Responsible for collaborating with the office staff to check medical } \\
\text { instructions and treatment and prepare all medications according to the } \\
\text { instructions. }\end{array}$ \\
\hline $\mathrm{D}$ & 24 & $\begin{array}{l}\text { Responsible for the implementation of patients' treatment and nursing } \\
\text { measures, such as basic nursing, psychological nursing and health } \\
\text { education. }\end{array}$ \\
\hline E & 6 & $\begin{array}{l}\text { Responsible for soaking goggles, disinfecting the environment, organizing } \\
\text { supplies, disposing of medical waste, terminal treatment of transferred or } \\
\text { dead patients and assisting patients undergoing various examinations. }\end{array}$ \\
\hline
\end{tabular}

that of medical staff who have received psychological intervention in response to disasters [12]. Therefore, in the early stage of the COVID-19 pandemic, a team of professional psychologists, using the WeChat platform, quickly started psychological intervention services and provided psychological counseling for the medical staff. In addition to paying attention to the emotional status of the nursing staff, ward managers should also acknowledge their own difficulties in life and work and seek necessary support in time to resolve their concerns.

\subsection{Ward Environment and Contaminant Disinfection Management}

The ward environment should be disinfected thoroughly. An air disinfection machine should be used for air disinfection, and the room should be ventilated 2 to 3 times a day for no less than $30 \mathrm{~min}$ each time. Visible contaminants on the surfaces of medical devices, bed rails, bedside cabinets, doorknobs and on the floor and wall should be cleaned and disinfected in a timely manner. In the absence of visible contaminants, the room should be disinfected by spraying, wiping or soaking with $1000 \mathrm{mg} / \mathrm{L}$ chlorine-containing disinfectant or $500 \mathrm{mg} / \mathrm{L}$ chlorine dioxide disinfectant 3 times a day, followed by rinsing with clean water 30 min later.

Contaminants discharged by patients, such as respiratory secretions, excreta, vomit and items contaminated by these contaminants, should be disinfected in a timely manner. Small amounts of contaminants can be carefully removed using disposable absorbent materials (such as gauze and rags) dipped in 5,000 - 10,000 $\mathrm{mg} / \mathrm{L}$ chlorine-containing disinfectant. Large amounts of contaminants should be completely covered with disinfection powder or bleaching powder containing water-absorbing components or first completely covered with disposable water- 
absorbing material and then rinsed with sufficient 5,000 - 10,000 mg/L chlorine-containing disinfectant on top of the water-absorbing material for more than 30 min. Patients' excreta, secretions and vomit should be collected in specialized containers and disinfected with $20,000 \mathrm{mg} / \mathrm{L}$ chlorine-containing disinfectant with a 1:2 feces to disinfectant ratio for 2 hours. After removing the contaminants, the containers should be soaked with disinfecting solution containing $5000 \mathrm{mg} / \mathrm{L}$ of available chlorine for $30 \mathrm{~min}$ and rinsed clean.

Following patient discharge, the room should be thoroughly disinfected. The ward and bedding should be disinfected with ultraviolet light and an air disinfection machine for 1 hour. The bedding should then be reversed and disinfected for 1 hour. The beds and bedside cabinets should be disinfected with hydrogen peroxide. The sheets, comforter covers, pillowcases, blankets, comforter and pillows should be packed and sealed in double-layer yellow medical waste bags, clearly labeled, and transferred to the bedding and clothing warehouse for disinfection and cleaning, and the handover process should be recorded. Items to be taken with the patients during discharge should be wiped with $75 \%$ ethanol or sprayed with $1000 \mathrm{mg} / \mathrm{L}$ chlorine-containing disinfectant.

After patient death, the corpse should be disinfected in a timely manner, and movement of the corpse should be minimized. All open passages or wounds, such as the mouth, nose, ears, anus, and tracheotomy, should be filled with cotton balls or gauze soaked with 3000 - $5000 \mathrm{mg} / \mathrm{L}$ chlorine-containing disinfectant or $0.5 \%$ peroxyacetic acid. The corpse should be wrapped with double-layer cloth soaked in disinfectant, put in a double-layer corpse bag and transferred to a designated location in a specialized vehicle for cremation.

\subsection{Medical Protective Equipment and Medical Waste Management}

The early COVID-19 outbreak in Wuhan is very severe, and there is a shortage of medical protective equipment [13]. Properly managing medical protective equipment for the prevention and treatment of the pandemic, including implementation of medical treatment and safety regarding the health of medical personnel, is paramount. Therefore, ward managers should pay special attention to the management of medical protective equipment, implement unified management and carefully record the input and output of stock supplies of equipment. The protective equipment should be assigned scientifically and reasonably according to protective needs, and usage of the equipment should be recorded. Medical personnel should receive necessary PPE when carrying out treatments and nursing tasks. The excessive use of PPE should be prevented so that resources are not wasted.

Medical waste should be managed in strict accordance with relevant regulations for infectious disease-related medical waste [14]. All domestic waste should be treated as medical waste and collected in yellow trash bags. Medical waste collector should only collect medical waste at the entrances of the elevator for patients and their families and must not enter the ward. 


\subsection{Ward Layout Management}

The layout of ward should be optimized and renovated according to the measures against contact, droplet and air exposure. Medical staff must put on and take off PPE on dedicated floor and enter or exit the ward through a special elevator. The specific layouts of the floors are shown in Figure 1 and Figure 2.

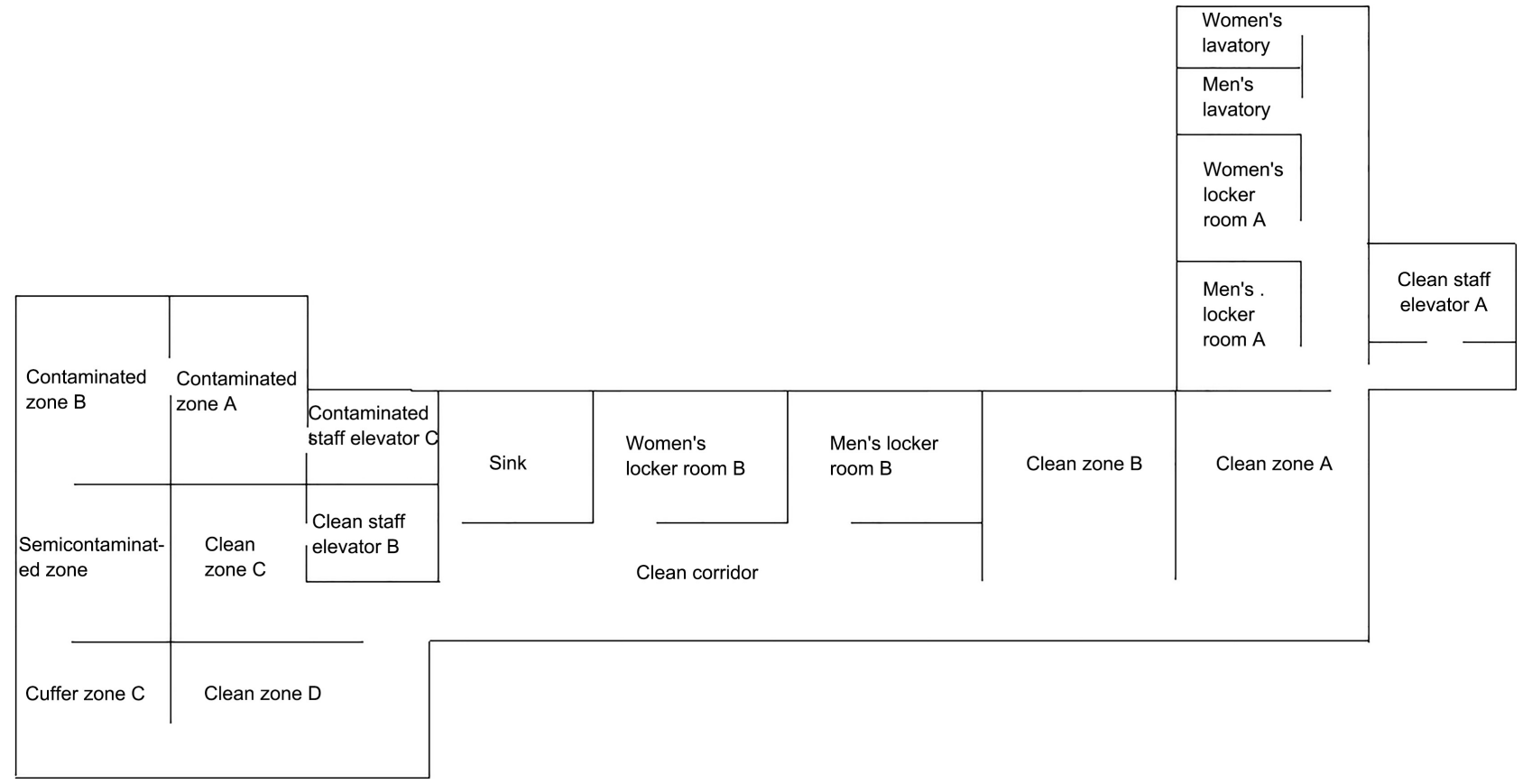

Figure 1. Zoning for medical personnel putting on and taking off PPE.

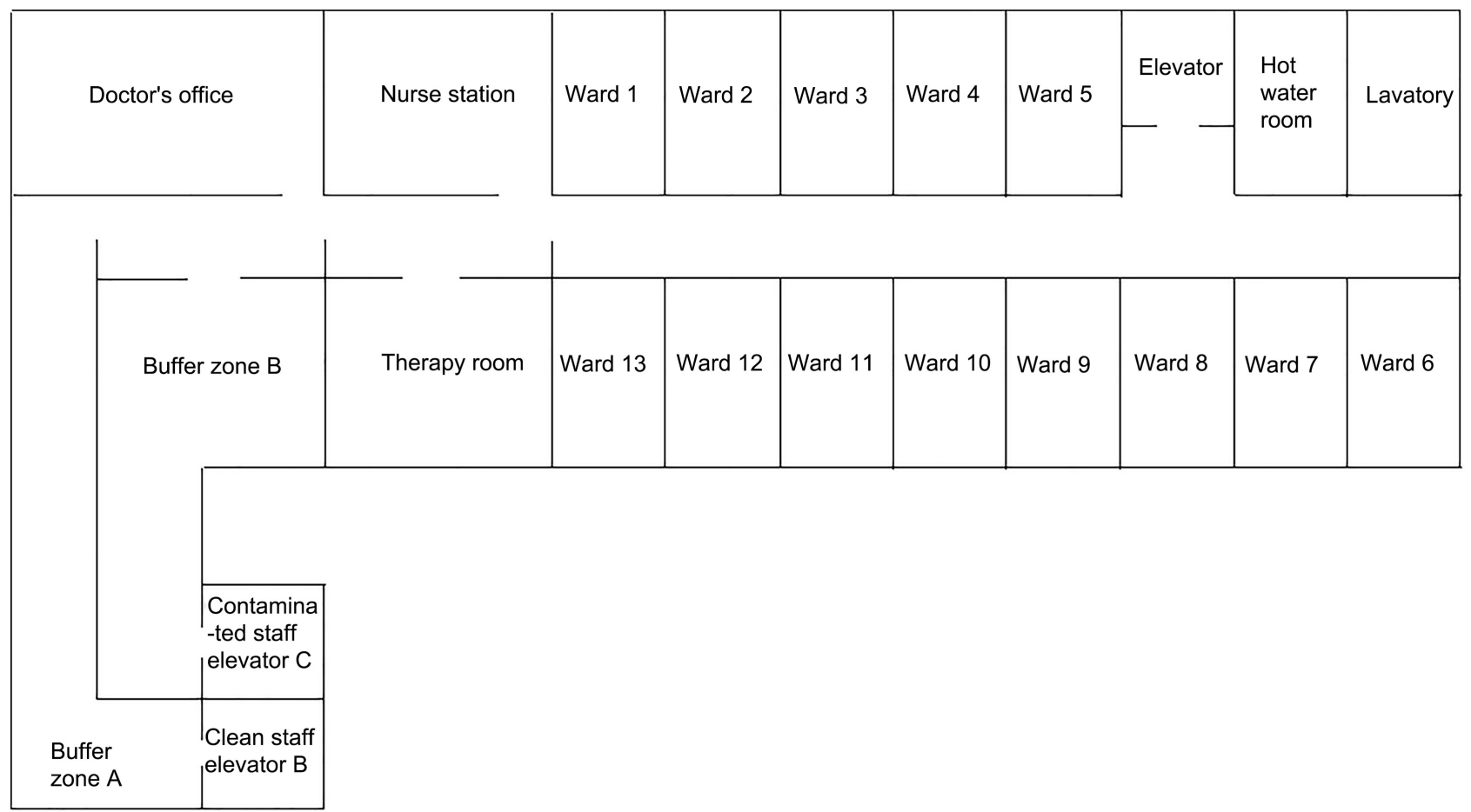

Figure 2. Organization of the isolation ward. 
Medical staff enter locker room A through clean staff elevator A, take off their outer layer of clothing and take relevant medications that enhance immunity through injection or oral administration in clean zone A. Medical staff then enter clean zone B, where they put on 2 masks (with an N95 respirator inside and a surgical mask outside), overalls and a disposable cap. In locker room $\mathrm{B}$, the medical staff wear gloves, personal protective clothing (PPC), waterproof shoe covers, goggles and a face shield. Lastly, they go to clean staff elevator B through clean zone $\mathrm{C}$ and arrive in buffer zone $\mathrm{A}$.

When leaving the ward, medical staff must go through buffer zone $B$ to enter contaminated staff elevator $\mathrm{C}$ and return to the floor designated for them to put on and take off PPE. The medical staff remove their face shield and waterproof shoe covers in contaminated zone A, PPC, outer layer of gloves and mask in contaminated zone B, goggles, overall, cap and inner layer of gloves in the semicontaminated zone, wear new masks in buffer zone $\mathrm{C}$ and enter clean zone D. After washing, the external ear canals and mucous membranes can be disinfected in clean zone A.

A safety supervisor should be assigned to each of the above zones to supervise and guide the medical staff in regard to wearing and taking off protective equipment. Contact with contaminated surfaces should be minimized when removing PPE. Nondisposable equipment, such as goggles, should be placed in receptacles containing disinfectants. Other disposable items should be placed in yellow medical waste bags as medical waste for centralized disposal. Hands should be disinfected at each PPE removal step, and after removing all PPE, hands should be washed and disinfected again.

\subsection{Care Quality Management}

During the COVID-19 pandemic, the ward implemented a 4-hour shift system, with 6 shifts per day. The head nurses dynamically allocated nursing staff according to the workload of the ward to ensure that nursing care in the ward was carried out smoothly and orderly and to prevent overworking the staff. All nursing staff members participated in relevant training, and each staff member passed an assessment. After working in the ward, the head nurses dynamically shared the latest rules and regulations through internet platforms, such as WeChat and QQ, so that the nursing staff could update their knowledge on protection and improve their overall protection standards and nursing abilities. Because the nursing staff devoted a lot of energy to prevention, in order to reduce the work intensity experience by the nursing staff, original nursing documents were streamlined and adapted to the actual nursing work.

\section{Conclusion}

SARS-CoV-2 is highly infectious and has spread worldwide, bringing great challenges to the global public health system. Zero infection among medical staff in isolation wards can be achieved by adjusting, nursing management strategies 
and controlling virus transmission through isolating infection sources, cutting off transmission routes and protecting the susceptible population. Excellent nursing management in COVID-19 isolation wards is extremely important for improving the treatment rate and ensuring zero infection among medical staff.

\section{Conflicts of Interest}

The authors declare no conflicts of interest regarding the publication of this paper.

\section{References}

[1] Chan, J.F., Yuan, S., Kok, K.H., et al. (2020) A Familial Cluster of Pneumonia Associated with the 2019 Novel Coronavirus Indicating Person-to-Person Transmission: A Study of a Family Cluster. The Lancet, 395, 514-523. https://doi.org/10.1016/S0140-6736(20)30154-9

[2] Li, Q., Guan, X., Wu, P., et al. (2020). Early Transmission Dynamics in Wuhan, China, of Novel Coronavirus-Infected Pneumonia. The New England Journal of Medicine, 382, 1199-1207. https://doi.org/10.1056/NEJMoa2001316

[3] World Health Organization (2020) Coronavirus Disease 2019 (COVID-19) Situation Report-200. 7 August 2020.

https://www.who.int/docs/default-source/coronaviruse/situation-reports/20200807covid-19-sitrep-200.pdf?sfvrsn=2799bc0f_2

[4] National Health Commission of the People's Republic of China (2020) Coronavirus Disease 2019 (COVID-19) Diagnosis and Treatment (Trial Version 7). 3 March 2020.

http://www.nhc.gov.cn/yzygj/s7653p/202003/46c9294a7dfe4cef80dc7f5912eb1989/fi les/ce3e6945832a438eaae415350a8ce964.pdf

[5] Huang, C., Wang, Y., Li, X., et al. (2020) Clinical Features of Patients Infected with 2019 Novel Coronavirus in Wuhan, China. The Lancet, 395, 497-506. https://doi.org/10.1016/S0140-6736(20)30183-5

[6] Holshue, M.L., Debolt, C., Lindquist, S., et al. (2020) First Case of 2019 Novel Coronavirus in the United States. The New England Journal of Medicine, 382, 929-936. https://doi.org/10.1056/NEJMoa2001191

[7] Chen, N., Zhou, M., Dong, X., et al. (2020) Epidemiological and Clinical Characteristics of 99 Cases of 2019 Novel Coronavirus Pneumonia in Wuhan, China: A Descriptive Study. The Lancet, 395, 507-513. https://doi.org/10.1016/S0140-6736(20)30211-7

[8] Ma, H.L., Tan, J.Y., Yang, L., et al. (2016) Current Evidence on Traditional Chinese Exercises for Cancer-Related Fatigue: A Quantitative Synthesis of Randomized Controlled Trials. European Journal of Integrative Medicine, 8, 707-714.

[9] Medical Panel of the First Affiliated Hospital of Sun Yat-sen University (2020) Diagnosis and Clinical Management of Severe 2019 Novel Coronavirus (2019N-CoV) Infection: Recommendations of The First Affiliated Hospital of Sun Yat-sen University (V 1.0). Journal of Sun Yat-sen University (Medical Sciences), 41, 161-173.

[10] Cai, M. and Wang, X. (2003) Practice and Effect of Setting up Safety Guards in SARS Wards. Journal of Nursing Administration, 3, 14-15.

[11] Ying, S., Zheng, L., Cao, L., Zhang, Y., Li, E. and Nian, S. (2020) Resilience of Nurses Against COVID-19 and Its Influencing Factors. Chinese Journal of Modern 
Nursing, 26.

[12] Fullerton, C.S., Ursano, R.J. and Wang, L. (2004) Acute Stress Disorder, Posttraumatic Stress Disorder, and Depression in Disaster or Rescue Workers. The American Journal of Psychiatry, 161, 1370-1376. https://doi.org/10.1176/appi.ajp.161.8.1370

[13] National Health Commission of the People's Republic of China (2020) Notice on Strengthening the Management of Medical Protective Equipment during the Epidemic. 3 February 2020.

http://www.gov.cn/zhengce/zhengceku/2020-02/04/content_5474521.htm

[14] The Central People's Government of the People's Republic of China (2003) Medical Waste Management Regulations.

http://www.gov.cn/banshi/2005-08/02/content_19238.htm 